\title{
Small hydropower plants as a threat to the endangered pearl mussel Margaritifera margaritifera
}

\author{
Ronaldo Sousa a,*, André Ferreira ${ }^{a}$, Francisco Carvalho a ${ }^{a}$, Manuel Lopes-Lima ${ }^{\mathrm{b}}$, Simone Varandas ${ }^{\mathrm{c}}$, \\ Amílcar Teixeira ${ }^{\mathrm{d}}$, Belinda Gallardo ${ }^{\mathrm{e}, \mathrm{f}}$ \\ a CBMA - Centre of Molecular and Environmental Biology, Department of Biology, University of Minho, Campus Gualtar, 4710-057 Braga, Portugal \\ ${ }^{\mathrm{b}} \mathrm{CIBIO} / \mathrm{InBIO}$ - Research Center in Biodiversity and Genetic Resources, University of Porto, Campus Agrário de Vairão, Vairão, Portugal \\ c CITAB-UTAD - Centre for Research and Technology of Agro-Environment and Biological Sciences, University of Trás-os-Montes and Alto Douro, Forestry Department, Vila Real, Portugal \\ d Centro de Investigação de Montanha (CIMO), Instituto Politécnico de Bragança, Campus de Santa Apolónia, 5300-253 Bragança, Portugal \\ e IPE-CSIC Pyrenean Institute of Ecology, Department of Biodiversity Conservation, Avda. Montañana 1005, 50059 Zaragoza, Spain \\ ${ }^{\mathrm{f}}$ BioRISC Biosecurity Research Initiative at St Catharine's, St Catharine's College, Cambridge CB2 1RL, UK
}

\section{H I G H L I G H T S}

- We assessed the impact of dams on the pearl mussel M. margaritifera.

- Pearl mussels were much more abundant upstream of dams.

- Juveniles were mostly found upstream of dams.

- Most significant alterations are related to changes in sediment and water chemistry.

- Dams significantly affected the abundance and size structure of pearl mussels.

\section{A R T I C L E I N F O}

\section{Article history:}

Received 3 December 2019

Received in revised form 13 February 2020

Accepted 14 February 2020

Available online 19 February 2020

Editor: Damia Barcelo

\section{Keywords:}

Conservation

Dams

Freshwater mussels

Habitat loss and fragmentation

Reservoirs

Unionids

\section{G R A P H I C A L A B S T R A C T}

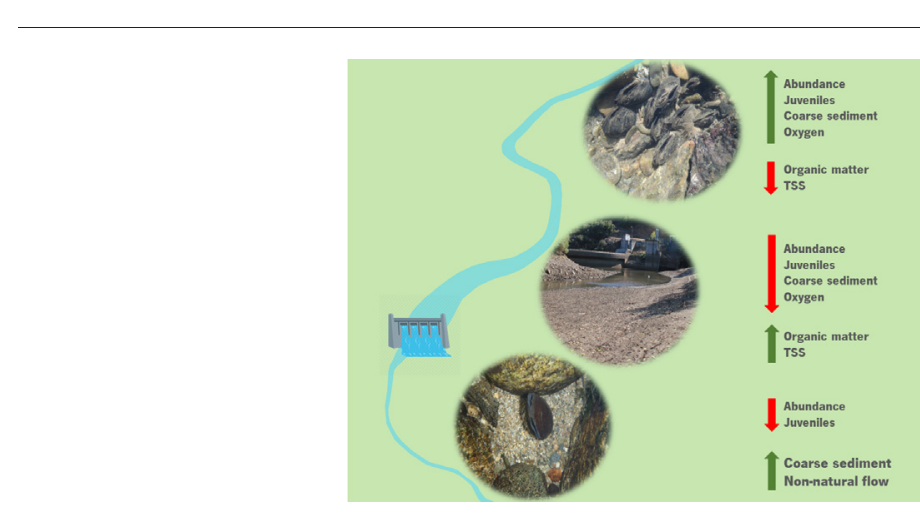

\begin{abstract}
A B S T R A C T
Freshwater mussels are undergoing rapid global declines due to habitat loss and fragmentation, among other factors, but little is known about the effects of small hydropower plants. Here we assessed the impact of small hydropower plants on the abundance and size structure of the imperilled pearl mussel Margaritifera margaritifera. For this, we sampled 66 sites in three Portuguese rivers (Mente, Rabaçal and Tuela) located upstream and downstream of dams and within the reservoirs. Pearl mussels were significantly more abundant upstream than downstream of dams (97.4\% more) or within reservoirs (98.5\% more). In addition, juveniles were mostly found upstream of dams. The most significant environmental alterations that explained the observed patterns were related to changes in sediment characteristics (accumulation of fine sediments and organic matter in reservoirs) and water chemistry, most notably suspended solids (highest values in reservoirs) and dissolved oxygen (lowest values in reservoirs). Overall, results show that small hydropower plants can deeply affect pearl mussel populations: specimens almost disappeared from the areas within the reservoirs and sites located downstream only retained adults without signs of recent recruitment. Future management measures devoted to the conservation of pearl mussels should take into account the results reported here to avoid the construction of new dams in pearl mussel rivers; improve management of the river flow in downstream areas; and consider the decommissioning
\end{abstract}

\footnotetext{
* Corresponding author.

E-mail address: rg.eco.sousa@gmail.com (R. Sousa).
} 
of dams in pearl mussel rivers with a particular attention devoted to the re-naturalization of river sections under the influence of the reservoir and downstream areas.

(c) 2020 Elsevier B.V. All rights reserved.

\section{Introduction}

Humans have extensively altered rivers through the construction of dams and other physical infrastructures to meet their water, food, energy, transportation and security needs (Baxter 1977; Nilsson et al., 2005). Water infrastructures are responsible for major changes in habitats that include: habitat fragmentation and loss of connectivity; alterations in channel geomorphology and floodplain disconnection; changes in abiotic conditions (e.g. depth, oxygen, sediment, current velocity, temperature, water transparency, and nutrients); modifications in the magnitude and timing of critical high and low flows; release of greenhouse gases; alterations in the continuity of matter and energy; among others (Baxter 1977; Poff et al. 1997, 2007; Nilsson et al., 2005; Fearnside and Pueyo 2012; Grill et al. 2019). All these environmental changes are responsible for modifications in aquatic (and also adjacent terrestrial areas) biota that include homogenization of communities, loss of functional diversity, increased mortality in lotic organisms, disruption of reproductive cues, interrupted migration, and changed food webs (Allan and Flecker 1993; Lytle and Poff 2004; Nilsson et al., 2005; Gallardo et al. 2008; Gallardo and Aldridge 2018; Moran et al. 2018; Anastácio et al. 2019).

The above mentioned ecological impacts are mainly studied during and immediately after the construction of large dams. In comparison, the potential ecological impacts due to the presence of small hydropower plants are less considered and very few studies assess ways to mitigate their effects (Sutherland et al., 2020); this situation can be problematic because there is a major increase in support of these smaller infrastructures (Couto and Olden, 2018; Lange et al., 2018; Muller, 2019). The definition of small hydropower plants vary immensely from country to country and broadly refers to facilities that produce less electricity and operate in smaller rivers as compared to large hydropower plants (Couto and Olden, 2018). In the same vein, small hydropower plants have a myriad of operation modes, flow control structures, and environmental impacts, turning the definition very ambiguous. In this study we consider a small hydropower plant an installation with $<10 \mathrm{MW}$ of generation capacity (Couto and Olden, 2018; Lange et al., 2018).

A recent global assessment advances a staggering number of 82,891 small hydropower plants that are operating or under construction in 150 countries and these numbers will probably increase further in the next decades (Couto and Olden, 2018). Usually, small hydropower plants are located in the upper parts of river basins (Zarfl et al., 2015; Lange et al., 2018), which are crucial for the maintenance of hydrologic connectivity, providing habitat for many species and important ecosystem services to humans. In addition, upstream areas are usually less disturbed by human activities and therefore constitute important areas for biodiversity conservation (Vörösmarty et al., 2010). Because of their relevant and unique ecological impacts, the transferability of knowledge and application of mitigation measures from large to small hydropower plants is not straightforward (Couto and Olden, 2018).

Freshwater mussels (Bivalvia, Unionida) may be highly impacted by the presence of hydropower plants (Vaughn and Taylor, 1999). These organisms rely on their benthic habits and so any change in the sediments and hydrology can severely impair their survival. Interest in the conservation of freshwater mussels has increased enormously in the last decades due to their significant and rapid decline (Lopes-Lima et al., $2014,2017,2018$ ), and because they are seen as good indicators of the ecological integrity of aquatic ecosystems (Santos et al., 2015; FerreiraRodríguez et al., 2019). For example, Lopes-Lima et al. (2020) emphasize the role of these organisms as indicator species and the importance of knowing the basic biological features of freshwater mussels given their fundamental ecological role, but also high sensitivity to habitat, water, and sediment quality, making these species important targets for environmental monitoring and conservation. Yet, the number of studies addressing the effects of dams on freshwater mussels is still insufficient (but see for example Vaughn and Taylor, 1999). This is alarming because the presence of dams or other types of physical infrastructures is almost always mentioned as a key threat to freshwater mussels (Strayer et al., 2004; Lopes-Lima et al., 2017, 2018; Zieritz et al., 2018a).

The freshwater pearl mussel Margaritifera margaritifera (Linnaeus, 1758 ) is listed as Endangered globally and Critically Endangered in Europe by the IUCN (Moorkens et al., 2017). Although its European distribution extends from Portugal to Russia, pearl mussel numbers have been declining extensively in the last decades (Geist, 2010; LopesLima et al., 2017). This species depends on salmonids to complete its life cycle since their larvae (glochidia) have to pass a stage parasitising trouts or salmons for a few months before metamorphosing into juveniles (Geist, 2010; Modesto et al., 2018). Pearl mussels are mainly present in oligotrophic rivers with coarse sediments comprising cobbles, gravel, and sand with very low organic matter content (Varandas et al., 2013). For this reason, changes after the construction of small hydropower plants in rivers inhabited by pearl mussels may negatively affect their distribution, abundance and size structure due to direct mortality or negatively affecting reproduction and/or recruitment. Impacts can be completely different in organisms inhabiting the reservoir compared to those in downstream and upstream areas. For example, negative effects are expected in the reservoirs because lotic habitats will become progressively more lentic, with the associated changes in water flow, temperature, accumulation of fine sediments, increase in organic matter content in the sediments, decrease in oxygen concentrations, among other factors. As natural flow is usually changed by these infrastructures, areas downstream of the dam can also be significantly affected due to changes in hydrology, sediments, temperature, and other abiotic features. Only areas upstream of the reservoir may maintain their abiotic conditions for the presence of pearl mussels. Nevertheless, pearl mussels may still be negatively affected due to the impact of hydropower plants on fish hosts, given that even small dams may restrict the distribution of fish hosts and in this way contribute to the decline or even extirpation of freshwater mussel species (Watters, 1996; Schwalb et al., 2011; Haag, 2012).

Although M. margaritifera has been the subject of a growing number of ecological studies (for a review see Geist, 2010) and is a major target of applied conservation projects (Life projects) in Europe (Lopes-Lima et al., 2017), we are not aware of any study addressing the possible long-term effects of hydropower plants on this species at the basin or population scale. Therefore, the main aims of this study were to: i) assess how small hydropower plants may affect population features (abundance and size structure) of pearl mussels; ii) identify the main environmental factors responsible for possible changes in the studied population features, and iii) discuss the possible conservation implications of small hydropower plants on pearl mussel populations and propose measures to mitigate potential negative effects. We hypothesize that the abundance (including the presence of juveniles) of pearl mussels will be much lower in areas within the reservoir when compared to upstream and downstream areas. We also hypothesize that the main mechanism responsible for these differences will be the presence of fine sediments, enriched with organic matter, within the reservoirs when compared to upstream and downstream areas. 


\section{Material and methods}

\subsection{Study area}

Mente, Rabaçal and Tuela Rivers, all located in the NE of Portugal (Fig. 1), are tributaries of the Tua River (Douro basin). The three rivers have a total length of 57, 88 and $102 \mathrm{~km}$, respectively, and share a similar climate, with precipitation and temperature having high seasonal and inter-annual variability (Oliveira et al., 2012). Variability in precipitation is responsible for high river flows (even major floods) during winter/early spring, with a gradual decline in the river flow throughout the year, reaching minimal values in the late summer/early autumn (Sousa et al., 2012, 2018).

Four small ( $<10$ MW of generation capacity; Couto and Olden, 2018) hydropower plants are present in the study area: two in the Rabaçal basin (Rebordelo and Bouçoais-Sonim), with the Rebordelo dam also influencing the lower section of the Mente River, and another two in the Tuela basin (Nunes and Trutas). All four dams are considered non-diversion with storage installations. The Rebordelo dam is operational since 2004, has a generation capacity of $8.75 \mathrm{MW}$ and a height of $35.5 \mathrm{~m}$, with a reservoir covering an area of $460,000 \mathrm{~m}^{2}$ and a total extension (from the beginning to the end of the reservoir) of $4 \mathrm{~km}$. The Bouçoais-Sonim became operational in 2004, has a generation capacity of 10.00 MW and a height of $43.0 \mathrm{~m}$, with a reservoir covering an area of $153,000 \mathrm{~m}^{2}$ and an extension of $2 \mathrm{~km}$. The Nunes dam begun its operation in 1994, has a generation capacity of $9.90 \mathrm{MW}$, a height of $21.5 \mathrm{~m}$, and an extension of $1.5 \mathrm{~km}$. The Trutas dam became operational in 2009, has a generation capacity of $1.5 \mathrm{MW}$, a height of $9 \mathrm{~m}$, and an extension of $0.6 \mathrm{~km}$.

Mente, Rabaçal and Tuela basins have a low human density, resulting in a low disturbance, high conservation value of the habitats present, and high freshwater biodiversity (Oliveira et al., 2012; Sousa et al., 2015, 2018). In fact, the upper catchments of the three rivers are mostly within the Montesinho Natural Park and represent important habitats (including the non-protected areas located downstream of the park) for threatened aquatic species (Sousa et al. 2015 and 2018). Recent studies showed that these three rivers present the largest, still recruiting and well preserved, pearl mussel populations in Portugal (Sousa et al., 2015).

\subsection{Sampling strategy}

In this study, Mente, Rabaçal and Tuela Rivers were surveyed during the end of July and beginning of August 2017. We choose this time of the year to conduct our sampling due to good visibility, low depth and

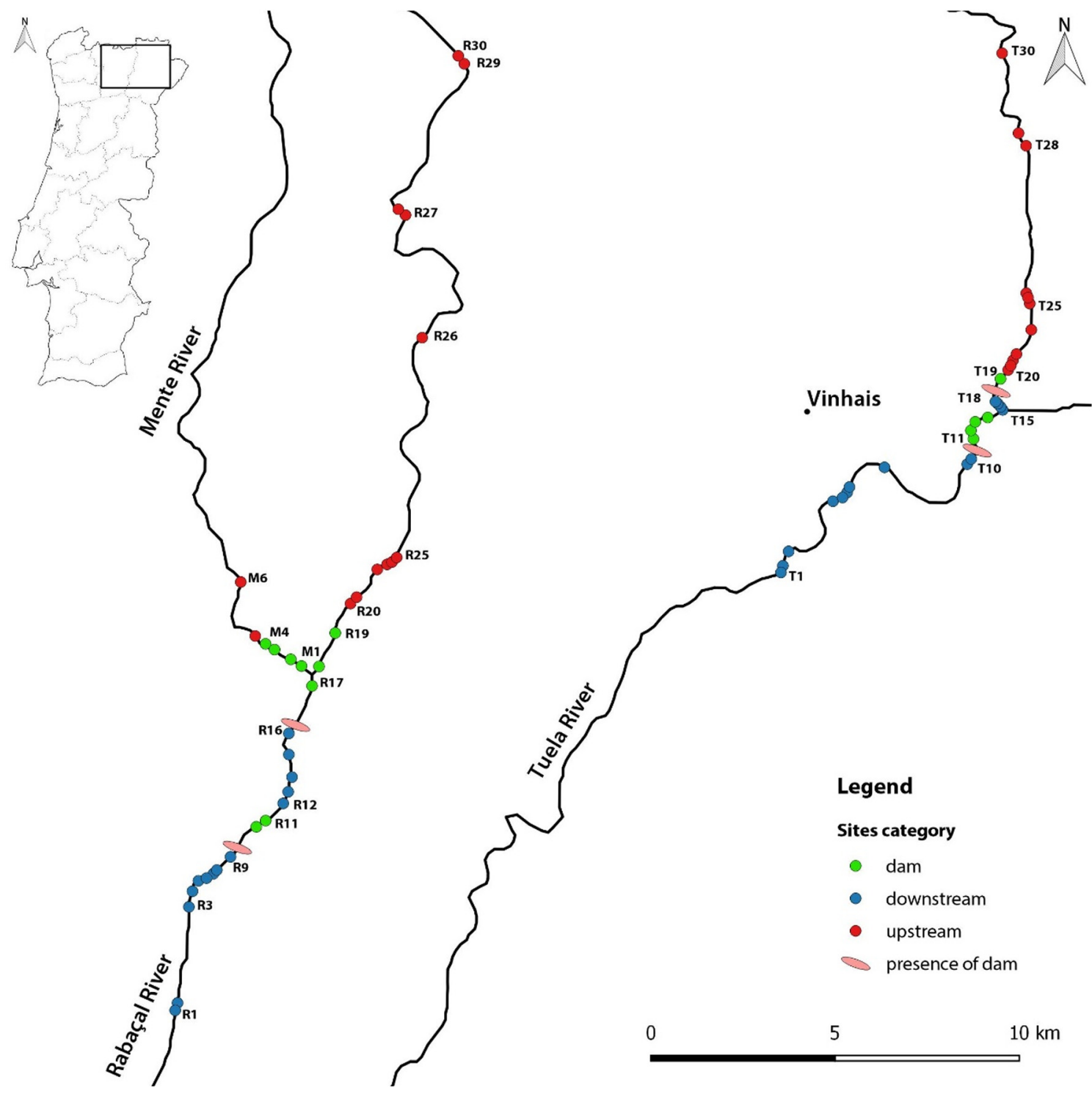

Fig. 1. Map showing the sampling site locations in Rabaçal (R), Mente (M) and Tuela (T) Rivers. 

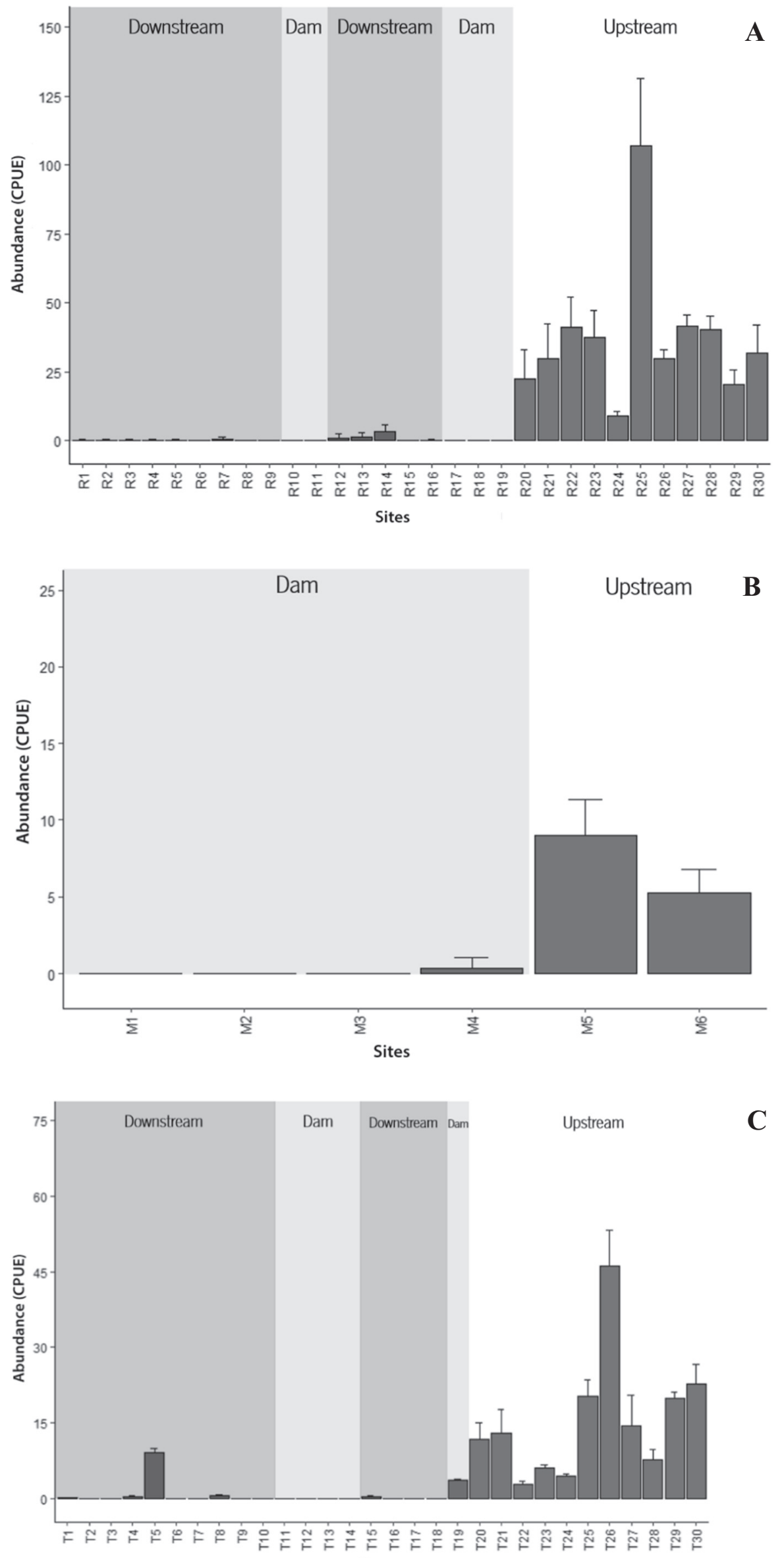
current velocity, which facilitate the detection of pearl mussels. In addition, earlier studies showed poor river bed quality, increased deposition of fine sediments and low oxygen during late summer low flows (Sousa et al., 2018, 2019), which should correspond to the worst-case abiotic conditions (possibly except for the environmental stress caused by high flows during winter conditions) for the presence of pearl mussels (Geist and Auerswald, 2007).

A total of 66 sites were sampled along the three rivers: 6 sites in Mente, 30 in Rabaçal and 30 in Tuela. Sites were chosen randomly, although spaced uniformly, and include downstream areas, where the distribution limit of pearl mussels is known (Sousa et al., 2015), and upstream areas located near the border with Spain. Sites were categorized as "downstream" (located downstream of dams), "dam" (within the reservoir) and "upstream" (located upstream the upper limit of the reservoir). In total, we sampled 28 sites categorized as downstream, 14 as dams and 24 as upstream.

River stretches of $50 \mathrm{~m}$ in length were sampled by snorkeling. Sampling methodology consisted of a variable number of 5 min dives performed by three or four experienced researchers. The number of dives per site varied between 4 and 12, being sites with lower abundances (i.e. we considered a low abundance site when after $30 \mathrm{~min}$ of sampling $<5$ individuals were collected) sampled with a higher effort. Even in sites within reservoirs, it was possible to snorkel due to the very low water level during the 2017 summer, in response to a severe drought (see for details Sousa et al., 2018 and Nogueira et al., 2020). In all sites, the number of pearl mussels was counted and each individual was measured using a digital caliper. Abundance was expressed by Catch Per Unit of Effort (CPUE) corresponding to individuals caught within 5 min of diving. After measurements, all organisms were carefully repositioned to their original locations.

In each sampling site, temperature, conductivity, dissolved oxygen, and $\mathrm{pH}$ were measured using a YSI EXO 2 multi-parameter probe. Water samples were also collected to determine total suspended solids (TSS) as well as total organic suspended solids (OSS). For this, water volumes of $1 \mathrm{~L}$ were filtered using GFC filters, which were dried at $60^{\circ} \mathrm{C}$ for $48 \mathrm{~h}$ and then heated in a muffle at $550^{\circ} \mathrm{C}$ for $8 \mathrm{~h}$. TSS and OSS were determined by weight difference (following Zieritz et al., 2016, 2018b). These measurements and water samples were always made/collected in the middle of the river near to the bottom at the end of the morning/beginning of the afternoon in four consecutive days at the beginning of August 2017. In addition, sediments were also collected in each site to determine the mean size granulometry and organic matter content, following the methodology described in Sousa et al. (2006, 2007). Sediment samples were collected in each site near $(2 \mathrm{~m}$ ) the left bank using a plastic cylinder with $10 \mathrm{~cm}$ of diameter and $60 \mathrm{~cm}$ of total length. Following Geist and Auerswald (2007) only the upper $10 \mathrm{~cm}$ layer was considered and the granulometry of each site was determined using a Ro-Tap agitator with a column of different sieves with different mesh sizes (from $<0.063 \mathrm{~mm}$ to $>90 \mathrm{~mm}$ ). Sediment of each class was expressed as a percentage of total weight. Organic matter in the sediment was determined, after combusting during $24 \mathrm{~h}$ at $550^{\circ} \mathrm{C}$, in a muffle furnace and values were expressed in percentage relative to the weight loss on ignition.

\subsection{Data analysis}

Differences in abundance and size of $M$. margaritifera between sites located upstream, downstream and within the reservoirs were assessed with non-parametric analyses of variance (Kruskal-Wallis test) since data depart from normality even after several transformations. Because data from the three rivers may violate the assumption of data independency, we calculated overall differences among upstream-damdownstream sites within each of the three rivers individually.
As potential predictors of the abundance of $M$. margaritifera we explored a total of 16 variables: eight related with water chemistry (temperature, conductivity, dissolved oxygen, pH, TSS, and OSS) and sediment characteristics (mean sediment size and percentage of organic matter content); and eight with the landscape, including four climatic (temperature seasonality, temperature of the warmest and coldest months, precipitation of the wettest month) and four human variables (distance to dams and roads, accessibility and the Human Influence Index) (Table S1, Supplementary Material). For landscape variables, we extracted the corresponding value from raster maps using the coordinates of each of the 66 sampling sites using a Geographic Information Systems (Q-GIS v 10.2). We summarized the mean and range of values observed in sampling sites upstream, downstream and within the reservoirs to illustrate differences among the three categories (Table S2, Supplementary Material). We conducted an exploratory Principal Component Analysis (PCA) to look for major differences between sampling sites located upstream, within and downstream of dams. Data were scaled ( mean $=0$ and $s d=1$ ) before analysis to avoid problems related to differences in sampling units.

To find key environmental predictors explaining $M$. margaritifera abundance, we first analysed pairwise Pearson's correlations and selected 10 variables with $r<|0.7|$ for further modelling (Fig. S1, Supplementary Material): Location (upstream, dam, downstream), five indicators of water and sediment conditions (OSS, temperature, $\mathrm{pH}$, conductivity and mean sediment size), two climatic (temperature seasonality and temperature of warmest month), and four human-related (distance to dams and roads, accessibility and the Human Influence Index). To account for the non-independence of observations among rivers, we fitted a Generalized Linear Mixed Model using the log-transformed CPUE as response variables and the set of 10 potential fixed predictors. To fix the random part of the model, we tested a null (no fixed factors) model with three options: random River (Akaike's Information Criterion with small-sample correction $[$ AICC $]=241)$, random Location ( AICC $=145)$, and random Location nested within River (AICC = 139). We chose the latter as the option with the lowest AICc. We then used multimodel inference ('MuMIn' package in R; Barton, 2011) to explore all combinations of predictors and ranked models using the Akaike Information Criterion corrected for small sample size (AICc). We considered all model combinations with $\triangle \mathrm{AICc}<2$ as equally valid to explain variation in the abundance of $M$. margaritifera and ranked explanatory variables by their frequency of selection. Finally, we used results from the first ranked model and checked the model fit, including any potential spatial correlation of the residuals through: normal Q-Q plots, residuals vs fitted values plot, and a semi-variogram to test for the spatial correlation of model residuals. None of these plots and analyses suggested the need for incorporating a spatial autocorrelation structure to the model.

Statistical analyses were conducted using packages "corrplot", "mgcv", "ggplot2", "gstat" and "MuMin" in R.

\section{Results}

\subsection{Effects of dams on the abundance and size of Margaritifera margaritifera}

In Rabaçal River, pearl mussels were present in 21 of the 30 sampled sites. Rabaçal River presents the highest abundance of pearl mussels with an average of 9.30 CPUE, with R25 showing the highest value (i.e. 107 CPUE). A clear difference was observed in the average abundances recorded in sites upstream of dams compared to sites downstream and within reservoirs (Kruskal-Wallis test, Chi-sq $=167.49$, df $=2, \mathrm{P}<0.001$ ). Sites upstream had an average abundance of 37.35 CPUE contrasting with average values of 0.54 and 0 CPUE in downstream and within the reservoir, respectively (Fig. 2A). In Mente River, 
pearl mussels were only present in 3 of 6 sampled sites. The average abundance of pearl mussels was 1.70 CPUE, presenting M5 the highest value with 9.00 CPUE (Fig. 2B). A clear difference was detected between sites located upstream, with an average of 7.13 CPUE, in comparison to sites located within the reservoir, with an average of 0.08 CPUE (Kruskal-Wallis test, Chi-sq $=38.54, \mathrm{df}=1, \mathrm{P}<0.001$ ). In Tuela River, pearl mussels were present in 17 of the 30 sampled sites. Tuela River presented an average abundance of 4.92 CPUE, with T26 showing the highest value (i.e. 46.25 CPUE). A clear difference was observed in the average abundances recorded in sites upstream of the dams compared to sites downstream and within reservoirs (Kruskal-Wallis test, Chi-sq $=138.04, \mathrm{df}=2, \mathrm{P}<0.001$ ). Sites upstream had an average abundance of 13.24 CPUE contrasting with average values of 0.59 and 1.28 CPUE in downstream and within the reservoir, respectively (Fig. 2C). Overall, and joining data from the three rivers, average abundance of pearl mussels in sites located upstream (22.00 CPUE) largely exceeded those found downstream (0.57 CPUE) and within the reservoirs $(0.33$ CPUE), with clear differences detected between treatments (KruskalWallis test, Chi-sq $=344.33, \mathrm{df}=2, \mathrm{P}<0.001$ ).

In Rabaçal River, the average size of the pearl mussels was $68.80 \mathrm{~mm}$, presenting the smallest specimen $17.00 \mathrm{~mm}$ (R23) and the largest $99.50 \mathrm{~mm}$ (R14). Site R28 (upstream) presented the lowest average size with $60.20 \mathrm{~mm}$ and $\mathrm{R} 4$ (downstream) the highest with $84.50 \mathrm{~mm}$ (Fig. 3A). A clear difference was observed in the average size recorded in sites upstream of the dams compared to sites downstream and within reservoirs (Kruskal-Wallis test, Chi-sq $=101.05, \mathrm{df}=2, \mathrm{P}<0.001$ ). The average size in sites located downstream was always higher than $77.00 \mathrm{~mm}$, with no individuals having $<60 \mathrm{~mm}$. In opposition, in upstream sites $14.75 \%$ of the individuals had $<60 \mathrm{~mm}$, being considered juveniles. In Mente River, the average size was $73.3 \mathrm{~mm}$, presenting the smallest specimen $59.00 \mathrm{~mm}$ (M6) and the largest $87.00 \mathrm{~mm}$ (M5). The average size was quite similar in M4, M5 and M6 (Fig. 3B) and only $1.28 \%$ of the individuals measured $<60.00 \mathrm{~mm}$. No differences were observed in the average size recorded in sites upstream of the dam compared to sites within the reservoir (Kruskal-Wallis test, Chi$\mathrm{sq}=0.01, \mathrm{df}=1, \mathrm{P}=0.917)$. In Tuela River the average size was $72.60 \mathrm{~mm}$, presenting the smallest specimen $29.00 \mathrm{~mm}$ (T24) and the largest $100.00 \mathrm{~mm}$ (T30). Site T24 (upstream) presented the lowest average size with $66.10 \mathrm{~mm}$ and T5 (downstream) the highest with $83.20 \mathrm{~mm}$ (Fig. 3C), being 5.39\% of the specimens considered juveniles. A clear difference was observed in the average size recorded in sites upstream of the dams compared to sites downstream and within reservoirs (Kruskal-Wallis test, Chi-sq $=92.56, \mathrm{df}=2, \mathrm{P}<0.001$ ). Overall, and joining data from the three rivers, the average size of pearl mussels found upstream was $69.60 \mathrm{~mm}$, which is similar to that within reservoirs $(70.80 \mathrm{~mm})$, but well below the $81.00 \mathrm{~mm}$ for the mussels located downstream. Clear differences in the size of pearl mussels were detected between treatments (Kruskal-Wallis test, Chi-sq $=199.12$, df $=2, \mathrm{P}<0.001$ ).

\subsection{Key environmental variables explaining Margaritifera margaritifera abundance}

The three first axes of the Principal Component Analysis explained a cumulative $72.8 \%$ of environmental variation in the dataset. The first axis (PC1, 30.1\% explained variance) was negatively correlated with suspended solids and organic matter; PC1 was positively correlated with $\mathrm{pH}$, dissolved oxygen and the size of sediments (see Table S3, Supplementary Material). This axis separated sites within reservoirs, at the left side of the graph, from sites upstream and downstream (Fig. 4). The second axis (PC2, 23.8\% explained variance) was positively correlated with temperature seasonality, water conductivity, human influence and distance to dams, and separated Tuela River sites (positive coordinates) from Mente and Rabacal River sites located at negative coordinates of this axis.

Multi-Model Inference identified seven possible combinations of variables as equally important predictors of the abundance of $M$. margaritifera. The most important predictors were: Location (included in all seven alternative models, $7 / 7$ ), organic suspended solids (7/7), the Human Influence Index (5/7) temperature seasonality (5/ $7)$; and to a lesser extent air temperature of the warmest month (1/7), distance to dams (1/7) and water temperature (1/7) (Fig. S2, Supplementary Material). The abundance of $M$. margaritifera was negatively influenced by high values of organic suspended solids, human influence, temperature and distance to dams (Fig. 5). The best GLMM model by AICc included as predictors location, organic suspended solids and human influence (adj- $\mathrm{R}^{2}=0.84$, correlation between observed and fitted values $=94 \%$ ). This model was not significantly different from the full model including all potential predictors (ANOVA, L-ratio = 3.25, $\mathrm{P}>0.05$ ). Diagnosis plots did not indicate any spatial correlation of the model residuals (Fig. S3, Supplementary Material).

Detailed abiotic data measured in situ in each sampling site can be consulted in Table S4 (Supplementary Material).

\section{Discussion}

In this study, and for the first time, we demonstrate that small hydropower plants affect the abundance and size structure of the endangered pearl mussel M. margaritifera. Despite many authors mentioned the presence of dams as a possible factor responsible for the decline of pearl mussels, we were not able to find any quantitative study directly addressing this topic (but see Addy et al., 2012). Overall, our results showed that sites subjected to reservoir conditions and those located downstream of dams suffer from severe habitat degradation and become unsuitable for the recruitment of juveniles or even the survival of adults. Moreover, we used water quality, climatic and human influence indicators to investigate the mechanisms that may drive changes in the species abundance. Therefore, the results reported here are very important for the current and future conservation and management of pearl mussels in dammed rivers.

\subsection{Small hydropower plants as a threat to Margaritifera margaritifera}

Small hydropower plants negatively affected the abundance and recruitment of $M$. margaritifera. These effects were more pronounced in areas within the reservoir where the abundance of pearl mussels dropped by $98.5 \%$, but downstream areas were also significantly affected with abundance values $97.4 \%$ lower than in upstream sites. It is important to note that the four dams in the study area have been operating recently and so this study showed that the decline of pearl mussels was very fast.

Although no detailed data exist regarding the abundance and size structure of pearl mussel populations before the construction of the four dams, it seems plausible that these facilities are the main factor explaining the significant reduction in abundance and lack of recruitment in sites within and downstream reservoirs. Indeed, human disturbance is quite low and we are not aware of possible pollution sources or sedimentation problems in the study area that could explain such an abrupt decline in abundance and absence of juveniles. While in the last years some negative effects on pearl mussel abundance have been reported from the predation of the signal crayfish Pacifastacus leniusculus (Sousa et al., 2019), the occurrence of an extreme flood in 2010 (Sousa et al., 2012) and an extreme drought in 2017 (Sousa et al., 2018; Nogueira et al., 2020), these factors are not enough to explain the patterns found. In fact, the impacts of the signal crayfish predation are more pronounced in upstream areas (Sousa et al. 2019), and the 

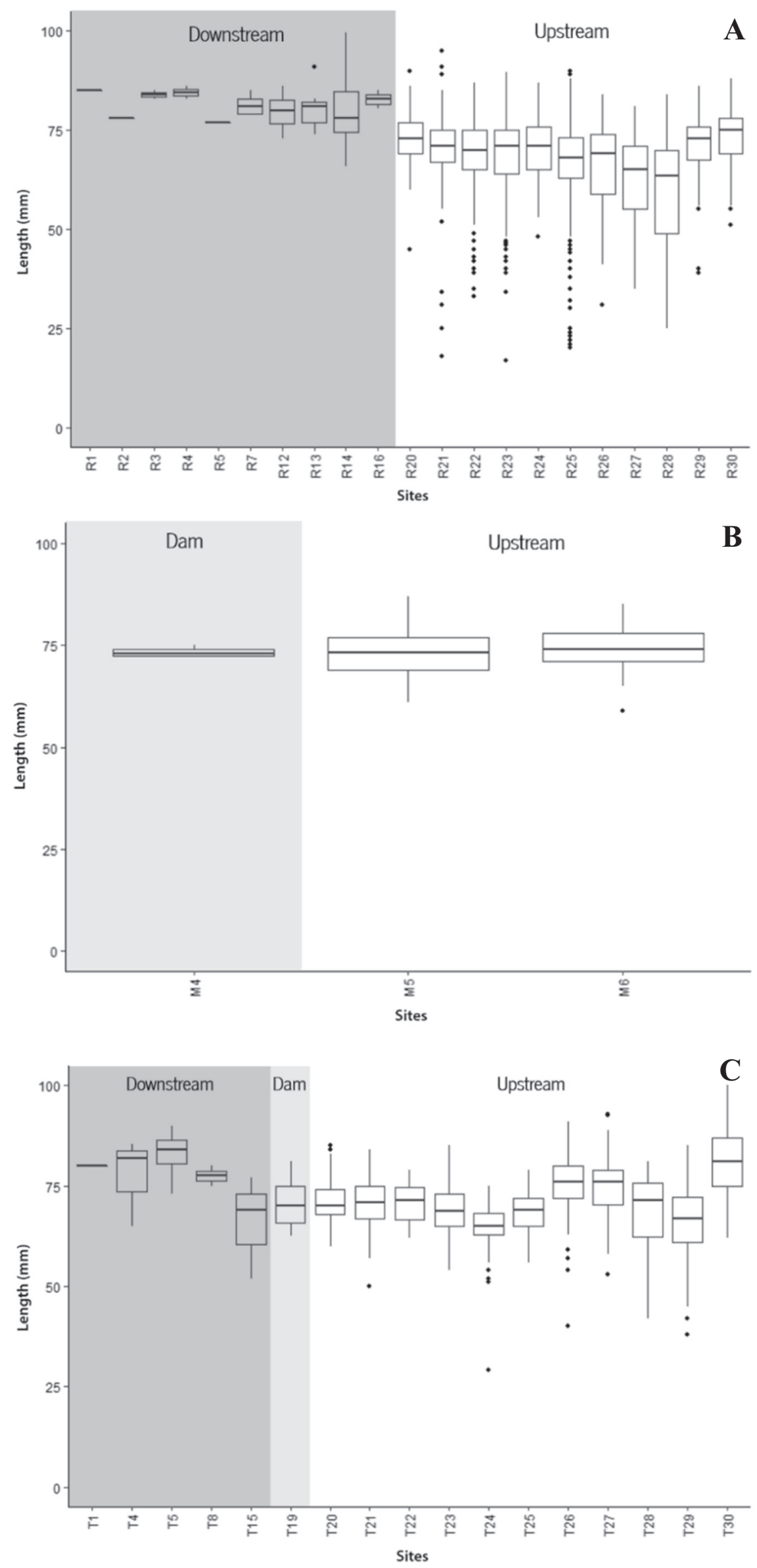


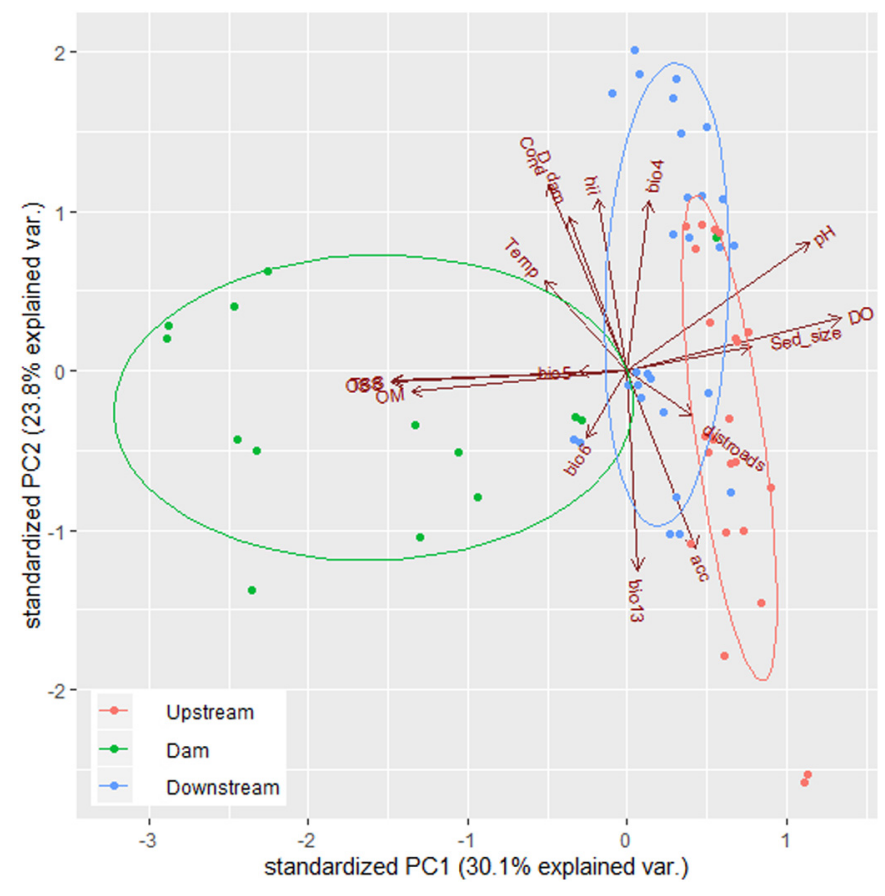

Fig. 4. Biplot of a Principal Component Analysis including water and sediment characteristics, climate and human influence indicators potentially explaining the abundance and size of Margaritifera margaritifera in Rabaçal, Mente and Tuela Rivers. Colour ellipses encompass samples collected upstream, downstream and within dams. More details about variables and results from PCA analysis can be consulted in Table S2 and S3 (Supplementary Material), respectively.

effects resulting from the extreme climatic events were similar in the three rivers and resulted in higher mortalities in the upstream areas (Sousa et al. 2012, 2018: Nogueira et al., 2020). Nevertheless, it is important to mention that mortalities reported for the 2017 drought occurred after the sampling performed in this study (i.e. mortality mainly occurred in late August and September; Sousa et al. 2018). We are confident that differences in abundance and size structure can be attributed to the presence of small hydropower plants as no other major factor acting at the basin scale seems to be in place.

Results come as no surprise since, when a river is dammed, the stretches subjected to lentic conditions provide a very different habitat in terms of sediments, water turbulence and stratification, oxygen and source of energy, among others (Couto and Olden, 2018). Pearl mussels occur only over a relatively narrow range of environmental characteristics, such as oligotrophic conditions, coarse sediments, lotic stretches, and relatively shallow areas (for a review on European populations see Varandas et al., 2013). Upstream areas in this study seem to present these favourable conditions and are mainly composed by coarse, noncompacted and well-sorted sediments, with almost no fine sediments and very low organic matter content (Fig. 6A). Highest pearl mussel abundances typically occur in riffle or shoal areas (Fig. 6B), precisely those habitats most affected by dams (Varandas et al., 2013; Sousa et al., 2015).

The presence of a small hydropower plant is responsible for the accumulation of fine sediments and high amounts of organic matter (leaf litter and deadwood), covering the earlier natural gravel and sand substrates, which are not suitable for pearl mussels (see Fig. 6C). For example, Geist and Auerswald (2007) clearly showed that functional populations of $M$. margaritifera inhabit areas with coarse and well-sorted sediments. Sites under reservoir influence present huge amounts of fine sediments and organic matter that completely change the environmental conditions of surface and hyporheic zones (Geist and Auerswald, 2007). In addition, areas rich in fine sediments have lower oxygen concentrations, a pronounced redox potential gradient, and higher sediment compaction (Geist and Auerswald, 2007). These environmental conditions can be especially detrimental to juveniles that live the first five years burrowed in the substrate (Geist, 2010). In our study area, the amount of fine sediments and organic matter is so high in sites under the reservoir influence (Fig. 6C), that even adults can be smothered. In fact, only in M4 and T19 we found alive specimens within the reservoir due to the fact that both sites are located near the upstream reservoir limit, with suitable substrate such as cobbles, pebbles, gravel and sands with no accumulation of fine sediment and
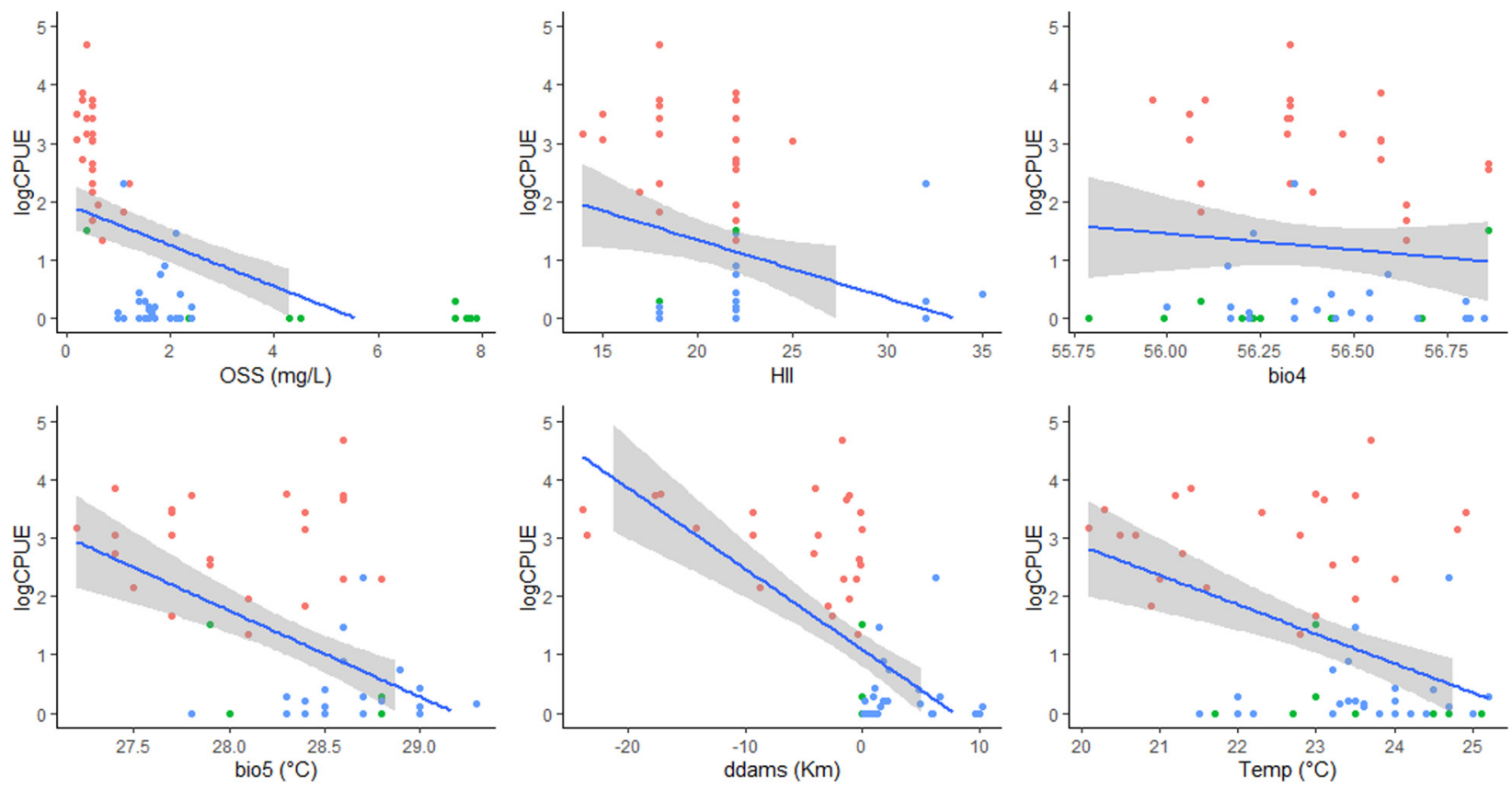

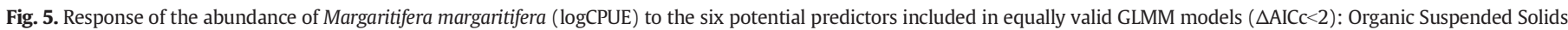

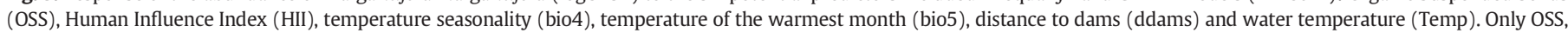

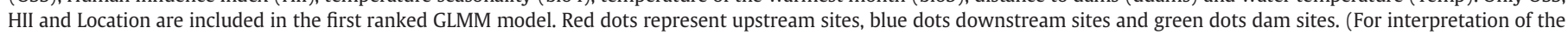
references to colour in this figure legend, the reader is referred to the web version of this article.) 

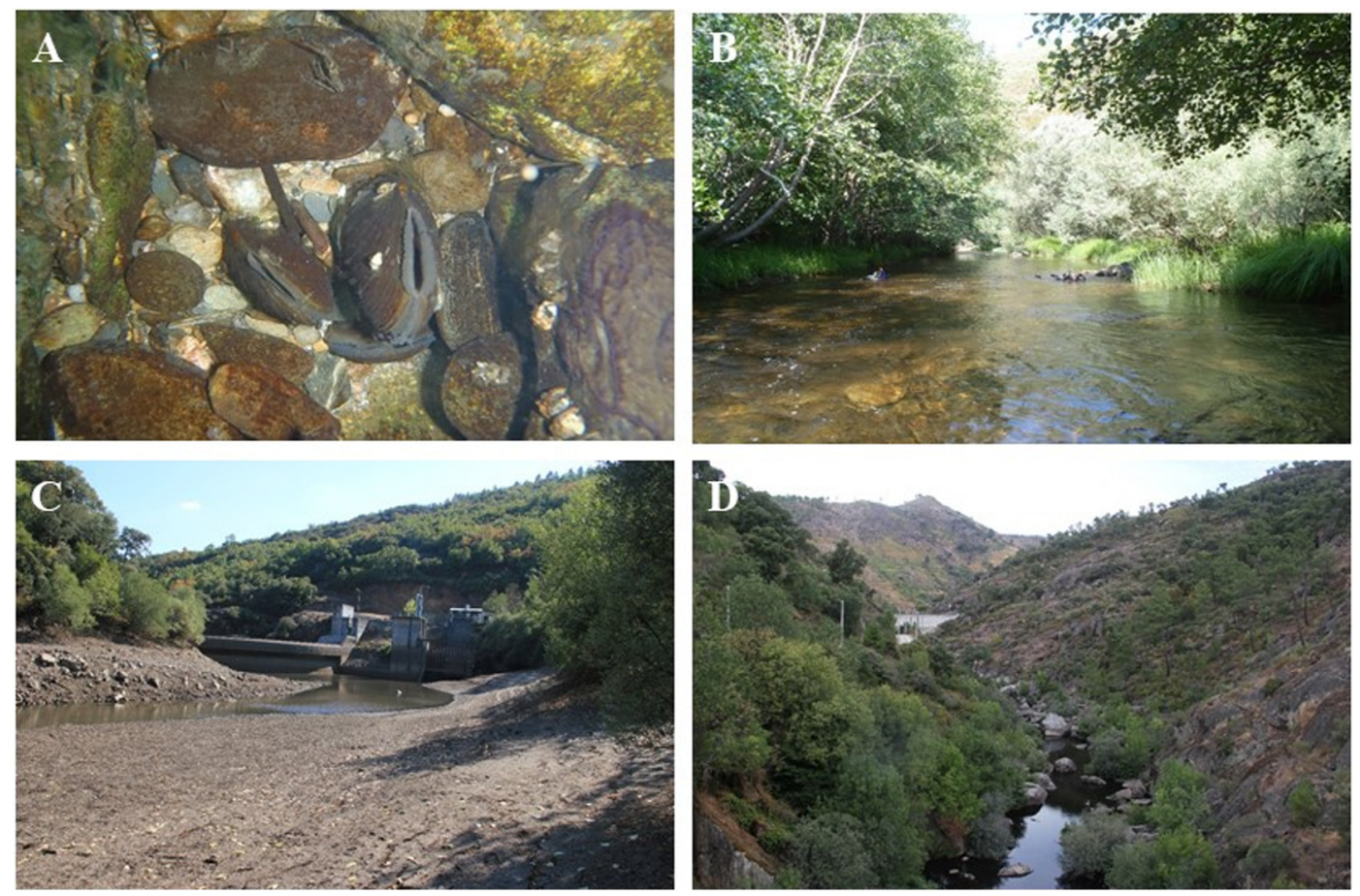

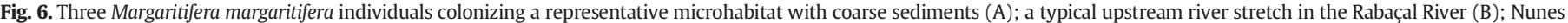

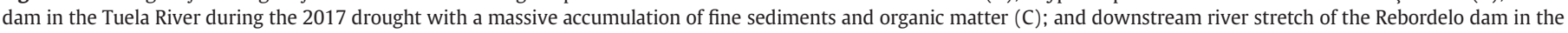
Rabaçal River (D).

organic matter. Sites within the reservoir also presented lower oxygen concentration and higher TSS and OSS values. The lower concentration in oxygen is probably a reflection of the lentic conditions during summer but also due to a higher amount of decomposing material when compared to upstream and downstream sites. Since pearl mussels are usually found in well-oxygenated habitats, the exposure to these low oxygen values during summer conditions might affect their survival. In addition, and since pearl mussels prefer oligotrophic conditions with very clear waters (Geist, 2010; Varandas et al., 2013), the high values of TSS and OSS reported in the majority of sites under reservoirs influence may also negatively affect their presence.

Although not so drastic as reported for sites within the reservoir, sites located downstream of dams also have a low abundance of pearl mussels and lack of juveniles. Below dams (Fig. 6D), significant changes in environmental factors may also occur. According to Addy et al. (2012), channel width may reduce considerably due to a reduction in competent flows caused by flow regulations. This situation may reduce the habitat availability, mainly near the banks, which is the preferred and more stable habitat for pearl mussels (Varandas et al., 2013). In addition, water released by dams may erode fine sediments from the banks and main channel in adjacent downstream areas, leading to the development of a coarse armoured surface layer that is not suitable for the burrowing of juveniles or adult pearl mussels (Addy et al., 2012). This situation was observed in our study area as the river is narrower in sites immediately downstream the dams and the sediment is coarser with almost no gravel and sands when compared to upstream sites. In winter (although not studied here), the river flow immediately below dams can be very high, which may wash adult and juvenile pearl mussels downstream from preferred to unsuitable habitats. The opposite may happen during summer conditions since the water released by dams may be too low (as during 2017; for details see Sousa et al., 2018), and may result in low water levels and pearl mussels stranded in the areas near the banks suffering high mortalities. Therefore, and even if areas immediately downstream of dams had in the past high abundances, it seems that after the dam started operating these sites have been highly impacted by hydrological (and consequently sedimentological) modifications. In addition, the temperature in the downstream sites may change because the water released by dams in the summer may have lower temperatures, due to reservoir water stratification (Vaughn and Taylor, 1999). Release of glochidia in pearl mussels occurs during late August and September and probably this species (although not studied here) has narrow windows during which environmental conditions are optimal. Given the great changes occurring within reservoirs and in downstream areas, our results suggest that the new environmental conditions are unsuitable for reproduction and recruitment, and consequently no juveniles were found downstream of dams. Although not assessed here, some studies have found that freshwater mussels colonizing downstream areas of dams with unnatural flow regimes have higher parasitism rates, and reduced body condition, which may also contribute to the lower abundances in these areas (Galbraith \& Vaughn, 2011). Finally, detrimental conditions in downstream areas may also affect the fish hosts and in this way be responsible for the lack of juveniles. A recent survey in the study area showed that brown trout have become extremely rare in these downstream areas (Sousa, personal observation). Similar results (i.e. drastic decline in abundance and diversity of freshwater mussels below dams) have been described in North American rivers (Layzer et al., 1993; Vaughn and Taylor, 1999).

\section{Conservation implications}

Pearl mussels have several life-history traits (e.g. long-lived, delayed reproduction and low juvenile survivorship; Geist, 2010) that make them highly susceptible to the impacts generated by hydropower plants. Adult pearl mussels are sedentary and have very low ability to seek refuge from certain disturbances (e.g. changes in sediment composition). Juveniles are even more affected because they have narrower ranges of tolerance to sedimentological and/or water chemistry changes, which presumably decrease overall recruitment and survival (Geist, 2010). Pearl mussels have a complicated life cycle, including a larval stage that is ectoparasitic on salmonids (salmon and trout). This situation turns the conservation of pearl mussels challenging because 
host fish can also be highly susceptible to the environmental changes generated by the presence of small hydropower plants. Overall, this study clearly showed that the presence of small hydropower plants can be responsible for the extirpation of pearl mussels under the influence of reservoirs. Even sites located downstream of dams can be highly affected and suffer local extinctions in the long-term due to the lack of recruitment. Only upstream areas in the study area seem to maintain optimal environmental conditions and these areas should be strictly protected. This is partly accomplished by the Montesinho Natural Park, but most of the conservation attention is devoted to the terrestrial biodiversity, overlooking freshwater species. Therefore, more attention should be given to upstream areas sheltering healthy pearl mussel populations and, for example, mitigate some of the already described impacts such as those related with droughts (Sousa et al., 2018; Nogueira et al., 2020) and the presence of non-native predators such as crayfish (Sousa et al., 2019). Also, and because a great part of upstream areas suitable for pearl mussels are outside the Montesinho Natural Park, a downstream extension of its coverage could considerably enhance the protection of freshwater biodiversity. Regarding areas within reservoirs, the restoration of the original abundance of pearl mussels is unlikely. In fact, and except for the Trutas dam that still presents good environmental conditions in the upstream edge of the reservoir, all the other sites within reservoirs have no conditions to restore the original habitat features unless decommissioning of the dams and re-naturalization of the habitats are implemented. In downstream areas, and also because the sedimentological conditions are similar to upstream areas (although with slightly higher grain size in sites immediately below the dams), and adult pearl mussels are still present, it is possible that the maintenance of a more natural flow will be the key to restore habitat conditions.

In conclusion, and because small hydropower plants affect the abundance and size structure of pearl mussels, future management measures devoted to the conservation of this species should consider the results reported here. These future measures include the prohibition of construction of new dams in pearl mussel rivers; improve management of river flow in downstream areas; and consider the decommissioning of old (or not viable) dams in pearl mussel rivers with a particular attention to the re-naturalization of river sections (and increase of pearl mussel abundance) under the influence of the reservoir and downstream areas.

\section{CRediT authorship contribution statement}

Ronaldo Sousa: Methodology, Resources, Formal analysis, Writing original draft. André Ferreira: Resources. Francisco Carvalho: Resources. Manuel Lopes-Lima: Resources. Simone Varandas: Resources. Amílcar Teixeira: Resources. Belinda Gallardo: Formal analysis.

\section{Declaration of competing interest}

The authors declare that there is no conflict of interests in this work.

\section{Acknowledgements}

This work was supported by: i) POSEUR-03-2215-FC-000096 and ICNF funds under project CP01-MARG-QUERCUS/2018; ii) Project Reviving Douro Basin funded by MAVA, Fondation pour la Nature and iii) European Investment Funds by FEDER/COMPETE/POCI - Operational Competitiveness and Internationalization Program, under Project POCI-01-0145-FEDER-006958 and National Funds by FCT - Portuguese Foundation for Science and Technology, under the projects UID/AGR/ 04033/2013 and UID/AGR/00690/2019. FCT also support MLL with a doctoral grant (SFRH/BD/115728/2016).

\section{Appendix A. Supplementary data}

Supplementary data to this article can be found online at https://doi. $\operatorname{org} / 10.1016 / j$.scitotenv.2020.137361.

\section{References}

Addy, S., Cooksley, S.L., Sime, I., 2012. Impacts of flow regulation on freshwater pearl mussel (Margaritifera margaritifera) habitat in a Scottish montane river. Sci. Total Environ. 432, 318-328

Allan, J.D., Flecker, A.S., 1993. Biodiversity conservation in running waters. BioScience 43 , 32-43.

Anastácio, P.M., Ribeiro, F., Capinha, C., Banha, F., Gama, M., Filipe, A.F., Rebelo, R., Sousa, R., 2019. Non-native freshwater fauna in Portugal: a review. Sci. Total Environ. 650 1923-1934.

Baxter, R.M., 1977. Environmental effects of dams and impoundments. Annu. Rev. Ecol. Syst. 8, 255-283.

Couto, T.B., Olden, J.D., 2018. Global proliferation of small hydropower plants-science and policy. Front. Ecol. Environ. 16, 91-100.

Fearnside, P.M., Pueyo, S., 2012. Greenhouse-gas emissions from tropical dams. Nat. Clim. Chang. 2, 382-384.

Ferreira-Rodríguez, N., Akiyama, B.Y., Aksenova, O., Araujo, R., Barnhart, C., Bespalaya, Y., Bogan, A., et al., 2019. Research priorities for freshwater mussel conservation assessment. Biol. Conserv. 231, 77-87.

Gallardo, B., Aldridge, D.C., 2018. Inter-basin water transfers and the expansion of aquatic invasive species. Water Res. 143, 282-291.

Gallardo, B., García, M., Cabezas, A., González, E., Ciancarelli, C., González-Sanchís, M. Comín, F.A., 2008. Macroinvertebrate patterns along environmental gradients and hydrological connectivity within a regulated river-floodplain. Aquat. Sci. 70, 248-258.

Geist, J., 2010. Strategies for the conservation of endangered freshwater pearl mussels (Margaritifera margaritifera L.): a synthesis of conservation genetics and ecology. Hydrobiologia 644, 69-88.

Geist, J., Auerswald, K., 2007. Physicochemical stream bed characteristics and recruitment of the freshwater pearl mussel (Margaritifera margaritifera). Freshw. Biol. 52, 2299-2316.

Grill, G., Lehner, B., Thieme, M., Geenen, B., Tickner, D., Antonelli, F., Babu, S., et al., 2019. Mapping the world's free-flowing rivers. Nature 569, 215-221.

Haag, W.R., 2012. North American Freshwater Mussels: Natural History, Ecology, and Conservation. Cambridge University Press, Cambridge.

Lange, K., Meier, P., Trautwein, C., Schmid, M., Robinson, C.T., Weber, C., Brodersen, J., 2018. Basin-scale effects of small hydropower on biodiversity dynamics. Front. Ecol. Environ. 16, 397-404.

Layzer, J.B., Gordon, M.E., Anderson, R.M., 1993. Mussels: the forgotten fauna of regulated rivers. A case study of the Caney Fork River. Regul. Rivers 8, 63-71.

Lopes-Lima, M., Teixeira, A., Froufe, E., Lopes, A., Varandas, S., Sousa, R., 2014. Biology and conservation of freshwater bivalves: past, present and future perspectives. Hydrobiologia 735, 1-13.

Lopes-Lima, M., Sousa, R., Geist, J., Aldridge, D.C., et al., 2017. Conservation status of freshwater mussels in Europe: state of the art and future challenges. Biol. Rev. 92 $572-607$.

Lopes-Lima, M., Burlakova, L.E., Karatayev, A.Y., Mehler, K., Seddon, M., Sousa, R., 2018. Conservation of freshwater bivalves at the global scale: diversity, threats and research needs. Hydrobiologia 810, 1-14.

Lopes-Lima, M., Hinzmann, M., Varandas, S., Froufe, E., Reis, J., Moreira, C., Araújo, S., Miranda, F., Gonçalves, D., Beja, P., Sousa, R., Teixeira, A., 2020. Setting the stage for new ecological indicator species: a holistic case study on the Iberian dolphin freshwater mussel Unio delphinus Spengler, 1793. Ecol. Indic. 111, 105987.

Lytle, D.A., Poff, N.L., 2004. Adaptation to natural flow regimes. Trends Ecol. Evol. 19, 94-100.

Modesto, V., Ilarri, M., Souza, A.T., Lopes-Lima, M., Douda, K., Clavero, M., Sousa, R., 2018. Fish and mussels: importance of fish for freshwater mussel conservation. Fish Fish 19, 244-259.

Moorkens, E., Cordeiro, J., Seddon, M.B., von Proschwitz, T., Woolnough, D., 2017 Margaritifera margaritifera. The IUCN Red List of Threatened Species.

Moran, E.F., Lopez, M.C., Moore, N., Müller, N., Hyndman, D.W., 2018. Sustainable hydropower in the 21st century. P. Natl. A. Sci. USA 115, 11891-11898.

Muller, M., 2019. Hydropower dams can help mitigate the global warming impact of wetlands. Nature 566, 315-317.

Nilsson, C., Reidy, C.A., Dynesius, M., Revenga, C., 2005. Fragmentation and flow regulation of the world's large river systems. Science 308, 405-408.

Nogueira, J.G., Lopes-Lima, M., Varandas, S., Teixeira, A., Sousa, R., 2020. Effects of an extreme drought on the endangered pearl mussel Margaritifera margaritifera: a before/after assessment. Hydrobiologia (in press).

Oliveira, J.M., Segurado, P., Santos, J.M., Teixeira, A., Ferreira, M.T., Cortes, R.V., 2012. Modelling stream-fish functional traits in reference conditions: regional and local environmental correlates. PLoSOne 7, e45787.

Poff, N.L., Allan, J.D., Bain, M.B., Karr, J.R., Prestegaard, K.L., Richter, B.D., et al., 1997. The natural flow regime. BioScience 47, 769-784.

Poff, N.L., Olden, J.D., Merritt, D.M., Pepin, D.M., 2007. Homogenization of regional river dynamics by dams and global biodiversity implications. P. Natl. A. Sci. USA 104, 5732-5737.

Santos, R.M.B., Sanches Fernandes, L.F., Varandas, S.G.P., Pereira, M.G., Sousa, R., Teixeira, A., Lopes-Lima, M., Cortes, R.M.V., Pacheco, F.A.L., 2015. Impacts of climate change and land-use scenarios on Margaritifera margaritifera, an environmental indicator and endangered species. Sci. Total Environ. 511, 477-488.

Schwalb, A.N., Cottenie, K.A.R.L., Poos, M.S., Ackerman, J.D., 2011. Dispersal limitation of unionid mussels and implications for their conservation. Freshw. Biol. 56, 1509-1518.

Sousa, R., Dias, S., Antunes, C., 2006. Spatial subtidal macrobenthic distribution in relation to abiotic conditions in the Lima estuary, NW of Portugal. Hydrobiologia 559, 135-148.

Sousa, R., Dias, S., Antunes, C., 2007. Subtidal macrobenthic structure in the lower Lima estuary, NW of Iberian Peninsula. Ann. Zool. Fenn. 44, 303-313. 
Sousa, R., Varandas, S., Cortes, R., Teixeira, A., Lopes-Lima, M., Machado, J., Guilhermino, L. 2012. Massive die-offs of freshwater bivalves as resource pulses. Ann. Limnol. Int. J. Limnol. 48, 105-112.

Sousa, R., Amorim, A., Froufe, E., Varandas, S., Teixeira, A., Lopes-Lima, M., 2015. Conservation status of the freshwater pearl mussel Margaritifera margaritifera in Portugal. Limnologica 50, 4-10.

Sousa, R., Ferreira, A., Carvalho, F., Lopes-Lima, M., Varandas, S., Teixeira, A., 2018. Die-offs of the endangered pearl mussel Margaritifera margaritifera during an extreme drought. Aquat. Conserv. 28, 1244-1248.

Sousa, R., Nogueira, J., Ferreira, A., Carvalho, F., Lopes-Lima, M., Varandas, S., Teixeira, A 2019. A tale of shells and claws: the signal crayfish as a threat to the pearl musse Margaritifera margaritifera in Europe. Sci. Total Environ. 665, 329-337.

Strayer, D.L., Downing, J.A., Haag, W.R., King, T.L., Layzer, J.B., Newton, T.J., Nichols, S.J., 2004. Changing perspectives on pearly mussels, North Americas most imperilled animals. Bioscience 54, 429-439.

Sutherland, W.J., Dias, M.P., Dicks, L.V., Doran, H., Entwistle, A.C., Fleishman, E., Gibbons, D.W., et al., 2020. A horizon scan of emerging global biological conservation issues for 2020. Trends Ecol. Evol. 35, 81-90.

Varandas, S., Lopes-Lima, M., Teixeira, A., Hinzmann, M., Reis, J., Cortes, R., Machado, J., Sousa, R., 2013. Ecology of southern European pearl mussels (Margaritifera margaritifera): first record of two new populations on the rivers Terva and Beça (Portugal). Aquat. Conserv. 23, 374-389.
Vaughn, C.C., Taylor, C.M., 1999. Impoundments and the decline of freshwater mussels: a case study of an extinction gradient. Conserv. Biol. 13, 912-920.

Vörösmarty, C.J., McIntyre, P.B., Gessner, M.O., Dudgeon, D., Prusevich, A., Green, P., Glidden, S., Bunn, S.E., Sullivan, C.A., Reidy Liermann, C., Davies, P.M., 2010. Global threats to human water security and river biodiversity. Nature 467, 555-561.

Watters, G.T., 1996. Small dams as barriers to freshwater mussels (Bivalvia, Unionoida) and their hosts. Biol. Conserv. 75, 79-85.

Zarfl, C., Lumsdon, A.E., Berlekamp, J., Tydecks, L., Tockner, K., 2015. A global boom in hydropower dam construction. Aquat. Sci. 77, 161-170.

Zieritz, A., Bogan, A.E., Froufe, E., Klishko, O., Kondo, T., Kovitvadhi, U., Kovitvadhi, S., Lee, J.H., Lopes-Lima, M., Pfeiffer, J.M., Sousa, R., Do, V.T., Vikhrev, I., Zanatta, D.T., 2018a. Diversity, biogeography and conservation of freshwater mussels (Bivalvia: Unionida) in east and Southeast Asia. Hydrobiologia 810, 29-44.

Zieritz, A., Bogan, A.E., Rahim, K.A., Sousa, R., Jainih, L., Harun, S., Razak, N.F.A., Gallardo, B., McGowan, S., Hassan, R., Lopes-Lima, M., 2018b. Changes and drivers of freshwater mussel diversity and distribution in northern Borneo. Biol. Conserv. 219, 126-137.

Zieritz, A., Lopes-Lima, M., Bogan, A., Sousa, R., Walton, S., Rahim, K., Wilson, J.-J., Ng, P.-Y., Froufe, E., McGowan, S., 2016. Factors driving changes in freshwater mussel (Bivalvia, Unionida) diversity and distribution in peninsular Malaysia. Sci. Total Environ. 571, 1069-1078. 